\title{
ANL/ET/CP-10004
}

\section{HYDRIDE-RELATED DEGRADATION OF SPENT-FUEL CLADDING UNDER REPOSITORY CONDITIONS*}

by

H. M. Chung

Argonne National Laboratory

Argonne, IL 60439, USA

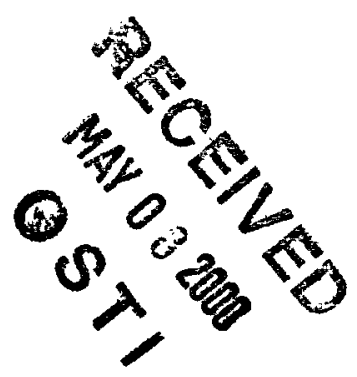

The submitted manuscript hax been created by the University of

Chicago an Operator of Argonne National Laboratory ("Argonne") under Contract No. W-31-109-ENG-38 with the U.S. Department of

Energy. The U.S. Government retains for itself, and others acting on

it behalf, a paid-up, nonexclusive, irrerocable worldwide license in

seid article to reproduce, prepare dertvative works, distribute

copiea to the public, and perform pubiscly and display publicly, by or on behalf of the Government.

February 2000

To be published in the Proc. of the Symposium on the Scientific Basis for Nuclear Waste Management XXIII, Materials Research Society Annual Meeting, Nov. 29-Dec. 3, 1999, Boston.

*Work supported by the U.S. Department of Energy, Office of Civilian Radioactive Waste Management, under Contract W-31-109-Eng-38. 


\section{DISCLAIMER}

This report was prepared as an account of work sponsored by an agency of the United States Government. Neither the United States Government nor any agency thereof, nor any of their employees, make any warranty, express or implied, or assumes any legal liability or responsibility for the accuracy, completeness, or usefulness of any information, apparatus, product, or process disclosed, or represents that its use would not infringe privately owned rights. Reference herein to any specific commercial product, process, or service by trade name, trademark, manufacturer, or otherwise does not necessarily constitute or imply its endorsement, recommendation, or favoring by the United States Government or any agency thereof. The views and opinions of authors expressed herein do not necessarily state or reflect those of the United States Government or any agency thereof. 


\section{DISCLAIMER}

Portions of this document may be illegible in electronic image products. Images are produced from the best available original document. 


\title{
HYDRIDE-RELATED DEGRADATION OF SPENT-FUEL CLADDING UNDER REPOSITORY CONDITIONS
}

H. M. Chung, heechung@anl.gov

Energy Technology Division, Argonne National Laboratory, Argonne, IL 60439

\begin{abstract}
This report summarizes results of an analysis of hydride-related degradation of commercial spent-nuclear-fuel cladding under repository conditions. Based on applicable laboratory data on critical stress intensity obtained under isothermal conditions, occurrence of delayed hydride cracking from the inner-diameter side of cladding is concluded to be extremely unlikely. The key process for potential initiation of delayed hydride cracking at the outer-diameter side is long-term microstructural evolution near the localized regions of concentrated hydrides, i.e., nucleation, growth, and cracking of hydride blisters. Such locally concentrated hydrides are, however, limited to some high-burnup cladding only, and the potential for crack initiation and propagation at the outer-diameter side is expected to be insignificant for most spent fuels. Some degree of hydride reorientation could occur in high-burnup spent-fuel cladding. However, even if hydride reorientation occurs, accompanying stress-rupture failure in spent-fuel cladding is unlikely to occur.
\end{abstract}

\section{INTRODUCTION}

Regulatory requirements on nuclear waste repositories specify that no more than one part in 100,000 of the radionuclides, calculated to be present 1,000 years after permanent closure of the repository, may be released annually from the engineered barrier system [1]. In spent-fuel rods, structural integrity of the cladding has been identified as one of the key factors that limits the release of radionuclides and significantly influences the overall performance of a repository system. However, potential degradation of microstructure and mechanical properties of spent-fuel cladding, e.g., via hydride-related processes, can be profound. The hydride-related degradation of Zircaloy cladding can be classified into two distinct aspects, delayed hydride cracking (DHC) and hydride reorientation. Extensive hydride reorientation could exacerbate not only the susceptibility to DHC but also the potential for outright stress-rupture failure. Because hydrogen uptake and hydriding are by far more significant in PWR cladding than in BWR cladding, the present analysis is focused on degradation of Zircaloy-4-clad PWR spent-fuel cladding.

\section{DELAYED HYDRIDE CRACKING}

\section{DHC in CANDU Pressure Tube and Laboratory Simulation Tests}

Delayed hydride cracking is a proven field event for Zircaloy- 2 and $\mathrm{Zr}-2.5 \% \mathrm{Nb}$ CANDU pressure tubes. Majority of the investigations on DHC, however, were conducted on compact-tension specimens under laboratory conditions. Cracking in a hydrogen-charged precracked compact-tension specimen occurs in three stages: When stress intensity is lower than a threshold level, commonly referred to as $\mathrm{K}_{\mathrm{IH}}$, an incipient crack or flaw is stable and does not propagate. When stress intensity exceeds the critical level $\mathrm{K}_{\mathrm{IH}}$ but is lower than the fracture toughness $\mathrm{K}_{\mathrm{IC}}$, a crack grows slowly at a stable rate. When stress intensity is greater than the fracture toughness $\mathrm{K}_{\mathrm{IC}}$, an unrestrained fast crack propagation occurs. Stress intensity is 
determined by: $\mathrm{K}_{\mathrm{IH}}=\sigma(\mathrm{a} \pi / 2)^{0.5}$, where $\mathrm{K}_{\mathrm{IH}}$ is stress intensity for DHC propagation (in MPa $\mathrm{m}^{0.5}$ ), $\sigma$ is stress (in $\mathrm{MPa}$ ), and $a$ is the crack size (in $\mathrm{m}$ ). The stable crack growth for $\mathrm{K}_{\mathrm{IH}}<\mathrm{K}<\mathrm{K}_{\mathrm{IC}}$ is attributed to $\mathrm{DHC}$, a process that repeats a cycle in which hydrogen solutes diffuse to the crack tip, hydrides precipitate at or near the crack tip, and, subsequently, the hydrides or the metallic region near the hydrides crack under stress and thus lead to a slowly advancing crack. Coleman showed elegant examples of hydrides that form nearly parallel to an advancing crack [2]. Test conditions of most accelerated laboratory investigations of DHC are characterized by several aspects, i.e., isothermal test condition, unirradiated hydrided specimen, Mode I compact-tension specimen, little or no residual stress in the specimen, negligible driving force for hydrogen diffusion due to temperature gradient, and short duration of testing. Based on laboratory studies of this type, a threshold stress intensity $\mathrm{K}_{\mathrm{IH}}$ of 5.5-8.0 $\mathrm{MPa} \mathrm{m}^{0.5}$ has been reported for CANDU pressure tube materials [3-5]. In contrast, Efsing and Petterson reported a somewhat higher value of $\mathrm{K}_{\mathrm{IH}}$ of 7.5-9.0 MPa $\mathrm{m}^{0.5}$ for unirradiated hydrided Zircaloy -2 at $\approx 300^{\circ} \mathrm{C}$ that contained $500-1000$ wppm hydrogen and exhibited a yield strength of 500-650 MPa [6]. Metallurgical factors that are relevant to field DHC (i.e., CANDU pressure tube failure), simulated crack growth tests in the laboratory, and PWR spent-fuel cladding under repository conditions are summarized in Table 1.

Table 1. DHC-relavant factors in CANDU pressure tubes, compact-tension specimens, and spent-fuel cladding.

\begin{tabular}{|l|l|l|l|}
\hline \multicolumn{1}{|c|}{ Factor } & \multicolumn{1}{|c|}{$\begin{array}{c}\text { CANDU Reactor } \\
\text { Pressure Tube }\end{array}$} & \multicolumn{1}{c|}{$\begin{array}{c}\text { Compact Tension } \\
\text { Specimen }\end{array}$} & \multicolumn{1}{c|}{$\begin{array}{c}\text { Spent-Fuel Cladding } \\
\text { in Repository }\end{array}$} \\
\hline Material & Zr-2.5Nb or Zircaloy-2 & Zr-2.5Nb,Zircaloys & Zircaloy-2,Zircaloy-4 \\
\hline DHC Proven & yes & yes & no \\
\hline Time to Occur & many years & several days & not known \\
\hline Hydrogen Source & coolant and moisture & precharged hydrogen & H in cladding, limited \\
\hline DHC Initiation at & OD hydride blisters & precrack tip & not known \\
\hline Temperature Gradient & $\begin{array}{l}\text { large }\left(\approx 00^{\circ} \text { C), at pressure }\right. \\
\text { tube and calandria contact }\end{array}$ & negligible & small, not known \\
\hline Stress Gradient & low & high & not known \\
\hline $\begin{array}{l}\text { Primary Driving Force for } \\
\text { Hydrogen Migration }\end{array}$ & temperature gradient & stress gradient & $\begin{array}{l}\text { stress gradient plus } \\
\text { temperature gradient }\end{array}$ \\
\hline Hydride Blistering & yes & no & not known \\
\hline Reoriented hydrides & precursor to blistering & yes & not known \\
\hline Concentrated Hydrides & yes, precursor to blistering & yes, near crack tip & some spots at high burnup \\
\hline Concentrated Oxygen & OD region beneath oxide & absent or negligible & OD region beneath oxide \\
\hline Applied Stress (MPa) & $=140$ & high & $60-130$ MPa \\
\hline Residual Stress & some & negligible & high near oD-side oxide \\
\hline
\end{tabular}

The occurrence of DHC in a CANDU pressure tube cannot be predicted from a threshold stress intensity $\mathrm{K}_{\mathrm{IH}}$ of $\approx 5.5 \mathrm{MPa} \mathrm{m}^{0.5}$. Crack initiation in the failed CANDU pressure tubes occurred not in association with fabrication-related flaws but in association with hydride blisters that formed on the outer-diameter (OD) side of the tube [7-11]. That is, long-term microstructural evolution was the key in crack initiation in the failed CANDU pressure tubes. The evolution can be divided into several processes: sagging of the horizontal hot pressure tube (maintained at $\approx 300^{\circ} \mathrm{C}$ ), contact of the tube $O D$ with the cold calandria tube (temperature $\approx 70^{\circ} \mathrm{C}$ ), $\mathrm{H}$ migration to the cold contact spot, nucleation of a hydride blister, growth of the hydride blister, crack initiation in the blister, and crack growth in the blister and adjacent metal.

\section{Potential for DHC Initiation at ID of Spent-Fuel Cladding in Repository}

Most incipient cracks in spent-fuel cladding, produced as a result of pelletcladding interaction or pellet-cladding mechanical interaction, are on the inner- 
diameter (ID) side. The potential for collecting $\mathrm{H}$, concentrated hydride precipitation, and hydride blistering in the ID region is insignificant or negligible because the temperature of the metal is higher on the ID side than at the midwall or OD side; and hence, the thermal driving force for $\mathrm{H}$ collection is either absent or negligible. Therefore, the conditions are similar to (or less deleterious than) those of the isothermal laboratory tests, and the critical stress intensity factor of $\approx 5.5 \mathrm{MPa} \mathrm{m}^{0.5}$ can be used to predict potential propagation of the incipient cracks. Oxide- or hydride-associated residual stress on the ID side is also small; therefore, the maximum stress on this side will not exceed $\approx 130 \mathrm{MPa}$, even for a burnup as high as $\approx 60 \mathrm{MWd} / \mathrm{kgU}$. Therefore, for an incipient crack on the ID side to propagate via the DHC mechanism, the crack size must exceed $\approx 1000 \mu \mathrm{m}$, or be greater than the thickness of PWR fuel cladding metal itself (i.e., $570-630 \mu \mathrm{m}$ ). Therefore, initiation and propagation of DHC on the ID side is not a concern under repository conditions.

\section{Potential for DHC Initiation at OD of Spent-Fuel Cladding in Repository}

Some regions of the OD side of the cladding under repository conditions will be cooler than other regions; therefore, there could be some degree of driving force for $\mathrm{H}$ solutes to migrate over a long period of time from the hotter regions to the colder metallic region at the OD side, under either temperature or stress gradients, or both. The key process for potential DHC initiation at the OD side, then, is potential longterm microstructural evolution, i.e., nucleation, growth, and cracking of hydride blisters in the metallic region, especially on some types of localized "hydrogencollecting spots." The "hydrogen-collecting" spots, characteristically colder and higher in stress, or both, could be locations near pellet/pellet boundaries, near pellet/pellet gaps, beneath a spacer grid, or beneath a spalled or radially cracked oxide layer. These spots are illustrated in Fig. 1. It is not clear if radial cracks in oxide, similar to those reported by Einziger and Kohli [12], could be produced as a result of long-term creep of the cladding, and if so, how they will potentially influence the susceptibilities to hydride blistering and blister cracking.

Evidence of concentrated hydrides in some high-burnup spent-fuel claddings has been reported near pellet/pellet interfaces [13,14], near pellet/pellet gaps $[14,15]$, and beneath a spalled oxide layer [14,16]. However, all of this evidence was observed only in PWR spent-fuel cladding fabricated from standard Zircaloy-4 (Sn content $\approx 1.5$ wt.\%) and operated to high burnup, e.g., $>55 \mathrm{MWd} / \mathrm{kgU}$. Oxidation and hydriding in standard Zircaloy-4 cladding have long been known to be high at high burnup. In contrast, the degree of oxidation and hydriding in present-day fuel claddings commonly used in light-water reactors, such as low-Sn Zircaloy-4, optimized Zircaloy-4, Zirlo, Zr-1Nb, and $\mathrm{Zr}$-lined Zircaloy-2, is relatively low even at high burnup. No evidence for concentrated hydrides has been reported for low or medium burnup. Therefore, formation of locally concentrated hydrides appears to be limited to a small fraction of spent-fuel cladding fabricated from standard Zircaloy-4 and operated to burnups close to $\approx 60 \mathrm{MWd} / \mathrm{kg}$. Consequently, although we cannot rule out or predict unequivocally that a hydride blister forms and grows near such locally concentrated hydrides under repository conditions, the potential for initiation of DHC near such concentrated hydrides is predicted to be insignificant for most commercial spent fuels.

\section{HYDRIDE REORIENTATION}

Hydride reorientation in spent-fuel cladding under dry storage conditions was investigated by Einziger and Kohli [12]. Hydride reorientation consists of dissolution of the normal circumferential hydrides as the temperature is increased above the heatup solubility limit, and precipitation of radial hydrides as the temperature is 
decreased below the cooldown solubility limit under stress. McMinn et al. reported that the heatup and cooldown solubility limits differ significantly, but the mechanism is not well understood [17]. The reorientation of hydrides is known to be strongly influenced by the stress [18-21] and texture [2] of the cladding; however, the effect of cooling rate has been reported to be insignificant [20]. Therefore, the minimum stress for reorientation applicable to spent irradiated cladding is of particular importance.

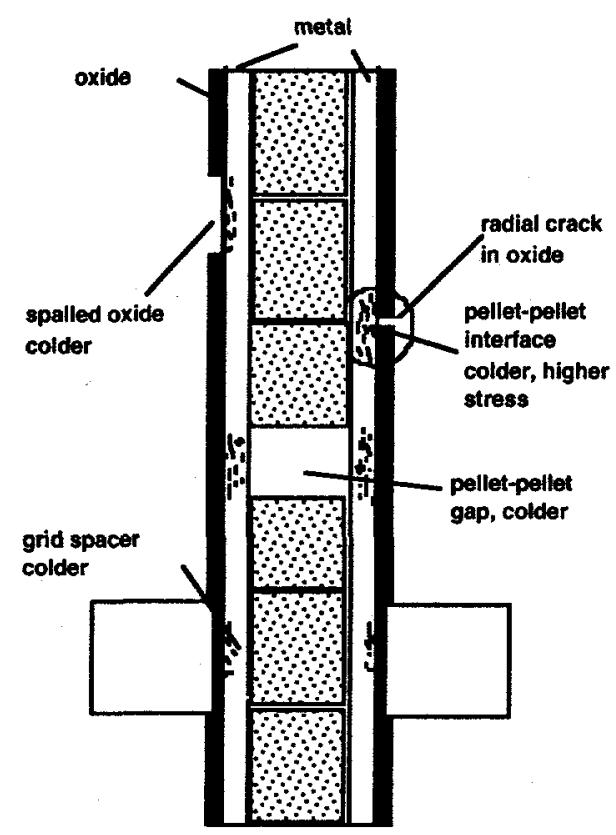

Fig. 1.

Illustration of potential spots for hydrogen concentration and hydride blister formation in spentfuel cladding

\section{Minimum Stress for Hydride Reorientation}

The minimum stress for hydride orientation in unirradiated specimens has been reported to be $\approx 85-95 \mathrm{MPa}[18-20]$. In contrast, Hardie and Shanahan reported an unusually low threshold stress of only $\approx 35 \mathrm{MPa}$ for $\mathrm{Zr}-2.5 \mathrm{Nb}$ pressure tube specimens [21]. However, the texture of their pressure tube specimen was entirely different from that of spent-fuel cladding, that is, the basal pole in the former material was $\approx 90^{\circ}$ away from the radial direction, whereas the basal pole of the latter is $\approx 30^{\circ}$ away from the radial direction. Because the basal planes are nearly parallel to the $\{107\}_{\mathrm{Zr}}$ habit plane of hydride precipitation, radial hydrides in the former material inherently precipitate more easily than those in the latter material. Therefore, the minimum stress reported by Hardie and Shanahan [21] does not seem to be applicable to spent fuel cladding. Einziger and Kohli observed reoriented (radial) hydrides in PWR spentfuel cladding (burnup $\approx 27-31 \mathrm{MWd} / \mathrm{kgU}$ ) that was exposed to $\approx 323^{\circ} \mathrm{C}$ for up to $\approx 87$ days and then cooled at a rate of $\approx 5^{\circ} \mathrm{C} / \mathrm{h}$ under an applied internal stress of $\approx 143 \mathrm{MPa}$ [12]. This level of stress significantly exceeds the minimum stress of $\approx 85-95 \mathrm{MPa}$ for hydride reorientation that was observed for unirradiated hydrided specimens. In view of this, reorientation of hydrides under repository conditions is expected to occur in some high-burnup spent-fuel cladding in which applied stress exceeds $\approx 90 \mathrm{MPa}$.

\section{Failure Stress of Hydride-Reoriented Spent-Fuel Cladding}

From the standpoint of structural integrity, the threshold stress for stressrupture failure of hydride-reoriented cladding is more important than the phenomenon of hydride reorientation itself. Data for such stress, however, are not available except for the experiment of Einziger and Kohli [12]. In that experiment, the cladding 
remained intact under an applied stress of $\approx 143 \mathrm{MPa}$ at $\approx 323^{\circ} \mathrm{C}$ for $\approx 87$ days and during subsequent cooling, despite the fact that extensive reorientation of hydrides occurred. The peak temperature is similar to that expected for spent-fuel cladding under repository conditions. Therefore, the experiment of Einziger and Kohli can be viewed as a conservative upper bound from the standpoint of the deleterious effect of hydride reorientation. Failure stress of spent-fuel cladding was reported by Chung et al. [22] for burnup of 22-28 MWd/kgU and by Garde [23] and Smith et al. [13] for burnups of 41-64 MWd $/ \mathrm{kgU}$. However, cladding specimens in these burst tests contained few radial hydrides before testing, although some high-burnup specimens may have contained localized radial hydrides, e.g., near pellet/pellet boundaries. Based on the information from these investigations, failure stress of the $\approx 30$ $\mathrm{MWd} / \mathrm{kgU}$ fuel cladding of Einziger and Kohli [12] is estimated to be $\approx 400 \mathrm{MPa}$ at $\approx 323^{\circ} \mathrm{C}$ when hydride reorientation did not occur. Therefore, the failure stress of the hydride-reoriented cladding would have been between $\approx 143$ and $\approx 400 \mathrm{MPa}$. Even the lower limit of $\approx 143 \mathrm{MPa}$ is significantly greater than a conservative internal stress of $\approx 70-90 \mathrm{MPa}$ that is estimated for burnups of $\approx 30 \mathrm{MWd} / \mathrm{kg}$. Therefore, it can be concluded that even if hydride reorientation occurs in some medium- and high-burnup spent-fuel cladding under repository conditions, subsequent stress-rupture failure in the hydride-reoriented cladding is not likely to occur.

\section{CONCLUSIONS}

Most incipient cracks in spent-fuel cladding are on the inner-diameter (ID) side. The thermal driving force for hydrogen concentration and the potential for hydride blistering on the ID side are insignificant or negligible because the temperature on the ID side is higher than on the outer-diameter (OD) side or at midwall. Therefore, the condition is similar to that of isothermal laboratory simulation tests of delayed hydride cracking (DHC), and the critical stress intensity factor of $\approx 5.5 \mathrm{MPa} \mathrm{m} \mathrm{m}^{0.5}$ can be used to predict potential propagation of incipient cracks at the ID. Based on this value of critical stress intensity, crack size distribution, and maximum applied stress, DHC from the ID side is extremely unlikely to occur.

Some regions at the OD side of the cladding under repository conditions will be somewhat cooler than other regions; therefore, there could be some degree of driving force for hydrogen solutes to migrate from the hotter ID and midwall regions to the metallic layer at the OD side, under either temperature or stress gradient, or both. The key process for potential DHC initiation at the OD side, then, is long-term microstructural evolution, i.e., nucleation, growth, and cracking of hydride blisters in the metallic region, especially on some types of localized hydrogen-collecting spots. The hydrogen-collecting spots, characteristically colder and higher in stress, or both, could be those near pellet-pellet boundaries, near pellet-pellet gaps, and beneath a spalled or radially cracked oxide layer. These local regions of concentrated hydrides are, however, limited to a small fraction of spent-fuel cladding fabricated from standard Zircaloy -4 and operated to burnup $>55 \mathrm{MWd} / \mathrm{kg}$. Consequently, potential for initiation of DHC near such locally concentrated hydrides is expected to be insignificant for most commercial spent fuels.

Texture plays an important role in reorientation of hydrides in $\mathrm{Zr}$-base alloy and Zircaloy tubings. Unusually low threshold stress for hydride reorientation reported for some $\mathrm{Zr}-2.5 \mathrm{Nb}$ pressure tube specimens is probably not applicable to commercial spent-fuel cladding, because the texture of the pressure tube specimens is entirely different from that of spent-fuel cladding. Some degree of hydride reorientation is expected to occur in high-burnup spent-fuel cladding under repository conditions. However, even if hydride reorientation occurs in some high-burnup spent-fuel cladding, accompanying stress-rupture failure in the hydride-reoriented cladding is not expected to occur. 


\section{ACKNOWLEDGMENTS}

This work was supported by the U.S. Department of Energy, Office of Civilian Radioactive Waste Management, under Contract W-31-109-Eng-38.

\section{REFERENCES}

1. Code of Federal Regulations 1997, Title 10 Part 60, Section 60.113, Article (a)(ii)(B), U.S. Government Printing Office, Washington DC, pp. 137.

2. Coleman, C. E. 1982, in Zr in the Nuclear Industry: 5th Intl. Symp., ASTM STP 754, D. G. Franklin, ed., ASTM, Philadelphia, p. 393.

3. Simpson, L. A. and Puls, M. P. 1979, Met. Trans. A, 10A, 1093.

4. Puls, M. P.; Simpson, L. A.; and Dutton, R. 1982, in Fracture Problems and Solutions in the Energy Industry, Pergamon Press, New York, pp. 13-25.

5. Shi, S.-Q. and Puls, M. P. 1996, in Hydrogen Effects in Materials, A. W. Thompson and N. R. Moody, eds., TMS, Warrendale, PA, p. 612.

6. Efsing, P. and Petterson, K. 1996, in $Z r$ in the Nuclear Industry: 11th Intl. Symp., ASTM STP 1295, E. R. Bradley and G. P. Sabol, eds., ASTM, Philadelphia, pp. 394.

7. Chow, C. K.; and Simpson, L. A. 1986, in Case Histories Involving Fatigue and Fracture Mechanics, ASTM STP 918, ASTM, Philadelphia, p. 78.

8. Cheadle, B. A.; Coleman, C. E.; and Ambler, J. F. R. 1987, in $\mathrm{Zr}$ in the Nuclear Industry: 7th Intl. Symp., ASTM STP 939, R. B. Adamson and L. F. P. Van Swam, eds., ASTM, Philadelphia, pp. 224-240.

9. Leger, M.; Moan, G. D.; Wallace, A. C.; and Watson, N. J. 1989, in Zr in the Nuclear Industry: 8th Intl. Symp., ASTM STP 1023, L. F. P. van Swam and C. M. Eucken, eds., ASTM, Philadelphia, pp. 50-65.

10. Coleman, C. E.; Cheadle, B. A.; Causey, A. R.; Chow, C. K.; Davies, P. H.; McManus, M. D.; Rodgers, D.; Sagat, S.; van Drunen, G. 1989, ibid., pp. 35-49.

11. Moan, G. D.; Coleman, C. E.; Price, E. G.; Rodgers, D. K.; and Sagat, S. 1990, Int. J. Pres. Vessel \& Piping, 43, 1-21.

12. Einziger, R. E. and Kohli, R. 1984, Nucl. Technol. 67, 107-123.

13. Smith Jr., G. P.; Pirek, R. C.; Freeburn, H. R.; and Schrire, D. 1994, The Evaluation and Demonstration of Methods for Improved Nuclear Fuel Utilization, DOE/ET/3401315, CEND-432, ABB Combustion Engineering, Windsor, CT, pp. 4-60 to 4-73.

14. Garde, A. M.; Smith, G. P.; and Pirek, R. C. 1996, in Zr in the Nuclear Industry: 11th Intl. Symp., ASTM STP 1295, E. R. Bradley and G. P. Sabol, eds., ASTM, Philadelphia, pp. 407-430.

15. Yang, R. L.; Ozer, O. and Klepfer, H. H. 1991, in Proc. Intl. Topical Meeting on LWR Fuel Performance, April 21-24, 1991, Avignon, France, ANS and ENS, pp. 258-271.

16. Guedeney, P.; Trotabas, M.; Boschiero, M.; Forat, C.; and Blanpain, P. 1991, in Proc. Intl. Topical Meeting on LWR Fuel Performance, April 21-24, 1991, Avignon, France, ANS and ENS, pp. 627-638.

17. McMinn, A.; Darby, E. C.; and Schofield, J. S. 1998, in Zr in the Nuclear Industry: 12th Intl. Symp., June 15-18, 1998, Toronto, in press.

18. Marshall, R. P. 1967, J. Nucl. Mater. 24, 34-48.

19. Bai, J. B.; Ji, N.; Gilbon, D.; Prioul, C.; and Francois, D. 1994, Met. Mater. Trans. A, 25A, 1 199-1208.

20. Chan, K. S. 1996, J. Nucl. Mater. 227, 220-236.

21. Hardie, D. and Shanahan, M. W. 1975, J. Nucl. Mater. 55, 1-13.

22. Chung, H. M.; Yaggee, F. L.; and Kassner, T. F. 1987, in $\mathrm{Zr}$ in the Nuclear Industry: 7th Intl. Symp., ASTM STP 939, R. B. Adamson and L. F. P. Van Swam, eds., ASTM, Philadelphia, pp. 775-801.

23. Garde, A. M. 1989, in Zr in the Nuclear Industry: 8th Intl. Symp., ASTM STP 1023, L. F. P. Van Swam and C. M. Eucken, eds., ASTM, Philadelphia, pp. 548-569. 